\title{
Dimensional ACCURaCy OF Models ManufaCtured by SELECTIVE LASER SINTERING TECHNOLOGY
}

\author{
Tomasz Kozior, Stanisław Adamczak, Michał Skrzyniarz, \\ Paweł Zmarzły \& Damian Gogolewski
}
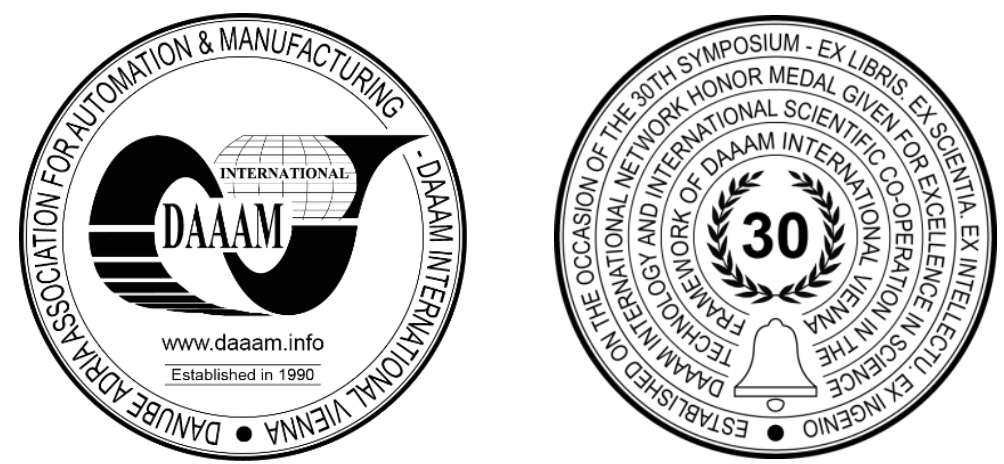

This Publication has to be referred as: Kozior, T[omasz]; Adamczak, S[tanislaw]; Skrzyniarz, M[ichal]; Zmarzly, P[awel] \& Gogolewski, D[amian] (2019). Dimensional Accuracy of Models Manufactured by Selective Laser Sintering Technology, Proceedings of the 30th DAAAM International Symposium, pp.0787-0790, B. Katalinic (Ed.), Published by DAAAM International, ISBN 978-3-902734-22-8, ISSN 1726-9679, Vienna, Austria DOI: $10.2507 / 30$ th.daaam.proceedings. 109

\begin{abstract}
The paper presents the results of the metrological research of models manufactured by additive manufacturing technology, selective laser sintering (SLS). Three type of placement of the cylindrical geometrical features of the model on the building platform during manufacturing where chose. Samples were prepared with polyamide powder PA 3200 GF (with addition of glass fibres). Coordinate measuring machine (Prismo Navigator, Zeiss) were employed to obtain measurements. Research results proved that location of geometrical features on the build tray (printing direction) has a major impact on their dimension accuracy. Both, the most and the least favourable location variants were determined.
\end{abstract}

Keywords: SLS; PA 3200 GF; CMM; Additive Manufacturing Technology; Polyamide.

\section{Introduction}

Additive technologies date back to the early 1980s. A turning point in the development of the above mentioned technologies was the year 2000, followed by the rapid commercialization of additive technologies and a significant drop in machine prices (3D printers). Originally, these technologies were used only to build individual prototype models of small size. With time, however, thanks to the development of technology, especially the increase in the precision of the manufactured of machine components (3D printers), the quality (accuracy) of models manufactured by additive technologies has improved. Currently produced machines have construction chambers of much larger dimensions, and model materials have both high mechanical properties and such operational features as, for example, bio-compatibility (SLS - PA 2200, according to EN ISO 10993-1) or high wear resistance. Elements manufactured by layered technologies become a kind of everyday life, in particular in the case of industrial applications. Currently, there are technologies that use materials based on plastics or even a metal materials [6], [7], [12], [19]. With the development of machines construction, there has been a progress in the technological capabilities of the manufacturing process. Currently, research is being carried out related to the possibilities of producing (printing) on existing models [3], [4], for example using FDM technology and ABS material. The mechanical properties of the models are good enough to allow the construction of 
prototype models for real functional tests, e.g. technical sealing elements [5] [16], [17], [18] bearings components [1] or pneumatic muscles [13].

Research related to determination of selected mechanical properties and dimensional-shape tolerance of models manufactured using SLS technology have been described in many research papers, among others [2], [9], [14]. The presented works related to both topics, the impact of technological parameters on the above-mentioned properties as well as innovative research related to the analysis of the properties of mixtures of polyamide powders [10], [11], also reinforced with, for example, the addition of aluminium. The analysis of the volumetric and anisotropic parameters of the geometrical structure of the surface, which analysis was presented in the work [15] is important in case of layered structure of model. In the case of conventional production technologies, e.g. milling process, the minimum value of the machined layer thickness is an important technological parameter [8], [20]. Additive manufacturing technologies have similar parameter, the minimum layer thickness, which has a direct impact on the accuracy and mechanical properties of models. In the presented research were analyse the influence of the technological parameter which is the direction of the location of geometrical features relative to the building platform on their accuracy.

\section{Methods}

The aim of the research was to determine the influence of placement the geometrical features (diameters and planes) of the models on the building platform on the dimensional and shape accuracy of the produced models (measurement of diameters, angles and flatness of the surface). The material used to build the sample was polyamide PA $3200 \mathrm{GF}$, which is additionally reinforced with fiberglass. The layer thickness was set as $0.1 \mathrm{~mm}$ and the temperature of the process chamber was $176{ }^{\circ} \mathrm{C}$. The dimensions of the test sample along with a model approximated by triangles are shown in Figure 1. The STL model was saved with approximation parameters, i.e. deviation tolerance (TO) 0.01, angle tolerance (TK) of $5^{\circ}$. Using the coordinate measuring machine Prismo Navigator, Zeiss, the diameters of holes made in three variants of location in relation to the building platform marked with numbering 1-3 were measured, and then by the point determination of the plane of the tested surfaces, both the inclination angles A1-E1, A2-E2 and $45^{\circ}$ (for diameter number 2) were calculated. In addition, the flatness of the tested surfaces was determined, A-E. The samples along with the supporting material, and then during the measurements process are shown in Figure 2. Three measurements of the tested values were made during the tests, and in Table 1 the mean value of the measurements were presented.
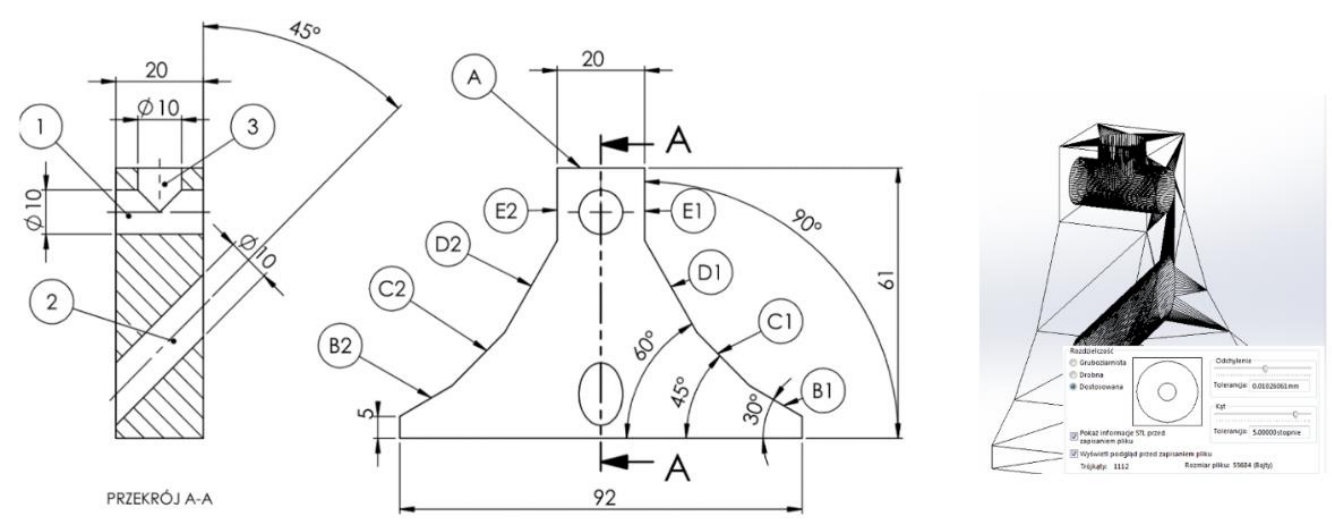

Fig. 1. Samples: Dimensions and STL approximation
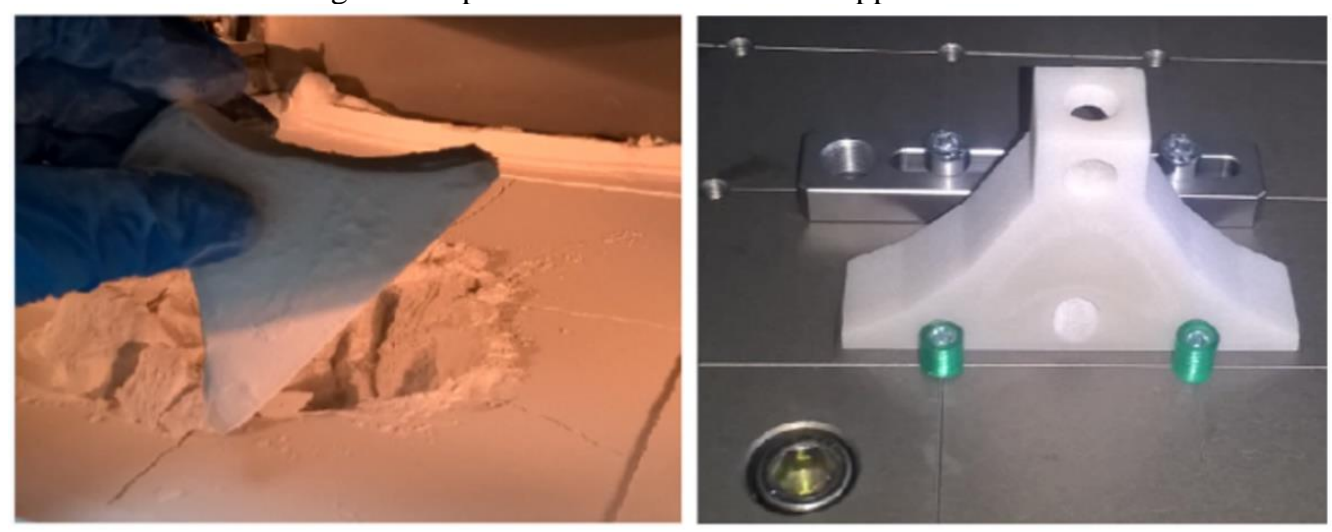

Fig. 2. Samples: cleaning process and measurements 


\section{Results}

Research results obtained by using coordinate measurement machine (angles and surface flatness deviation) have been presented in the table 1 . Moreover in table 2 diameter deviation for three type of the orientation samples on the building platform have been shown.

\begin{tabular}{|c|c|c|c|c|c|c|}
\hline \multicolumn{2}{|c|}{ Feature } & \multirow{2}{*}{$\frac{\text { Measure }}{36^{\circ} 12^{\prime} 18^{\prime \prime}}$} & \multirow{2}{*}{$\begin{array}{c}\text { Deviation } \\
-8^{\circ} 47^{\prime} 42^{\prime \prime}\end{array}$} & \multicolumn{2}{|c|}{ Feature } & \multirow{2}{*}{$\begin{array}{c}\text { Measure } \\
0.1117\end{array}$} \\
\hline \multirow{10}{*}{$\frac{0}{00}$} & $45^{\circ}$ & & & \multirow{10}{*}{ 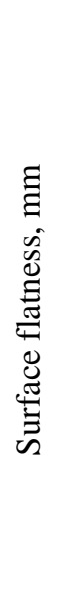 } & A & \\
\hline & A & $0^{\circ} 24^{\prime} 26^{\prime \prime}$ & $0^{\circ} 24^{\prime} 26^{\prime \prime}$ & & B1 & 0.0608 \\
\hline & B1 & $30^{\circ} 50^{\prime} 39^{\prime \prime}$ & $0^{\circ} 50^{\prime} 39^{\prime \prime}$ & & $\mathrm{C} 1$ & 0.0752 \\
\hline & $\mathrm{C} 1$ & $45^{\circ} 31^{\prime} 48^{\prime \prime}$ & $0^{\circ} 31^{\prime} 48^{\prime \prime}$ & & D1 & 0.1163 \\
\hline & D1 & $59^{\circ} 46^{\prime} 27^{\prime \prime}$ & $-0^{\circ} 13^{\prime} 33^{\prime \prime}$ & & E1 & 0.0671 \\
\hline & E1 & $89^{\circ} 10^{\prime} 8^{\prime \prime}$ & $-0^{\circ} 49^{\prime} 52^{\prime \prime}$ & & B2 & 0.0707 \\
\hline & B2 & $30^{\circ} 40^{\prime} 21^{\prime \prime}$ & $0^{\circ} 40^{\prime} 21^{\prime \prime}$ & & $\mathrm{C} 2$ & 0.0781 \\
\hline & $\mathrm{C} 2$ & $45^{\circ} 16^{\prime} 35^{\prime \prime}$ & $0^{\circ} 16^{\prime} 35^{\prime \prime}$ & & D2 & 0.0802 \\
\hline & D2 & $59^{\circ} 54^{\prime} 23^{\prime \prime}$ & $-0^{\circ} 5^{\prime} 38^{\prime \prime}$ & & $\mathrm{E} 2$ & 0.0864 \\
\hline & E2 & $89^{\circ} 20^{\prime} 21^{\prime \prime}$ & $-0^{\circ} 39^{\prime} 39^{\prime \prime}$ & & & \\
\hline
\end{tabular}

Table 1. Metrological research results

\begin{tabular}{ccccc}
\hline \multicolumn{2}{c}{ Feature } & Measure & Deviation & Tolerance class \\
\hline \multirow{3}{*}{$\varnothing, \mathrm{mm}$} & 1 & 9.4535 & -0.5465 & 15 \\
\cline { 2 - 5 } & 2 & 7.7163 & -2.2837 & 18 \\
\cline { 2 - 5 } & 3 & 9.6324 & -0.3676 & 14 \\
\hline
\end{tabular}

Table 2. Diameter deviation

Analyzing quantitatively the results of measurements of geometrical features of the examined surfaces, it can be stated that depending on the direction of their location relative to the construction platform, they are characterized by a certain degree of accuracy. For diameter measurements, the accuracy is in class respectivily 15 and 14 for angles $0^{\circ}$ and $90^{\circ}$, and in class 18 for $45^{\circ}$. Analyzing the results of side wall inclination measurements, it can be stated that the mean values of angular deviations are for SLS technology: $0^{\circ} 30^{\prime} 28^{\prime \prime}$. This deviation is caused by large internal stresses resulting from the material cooling process. This problem concerns many additive technologies such as SLS or SLM, where the high temperature of the building chamber (more than $170{ }^{\circ} \mathrm{C}$ ) generate unfavorable temperature gradients at the interface between the model and the suppor material. The measurement of flatness deviation of the tested surfaces presents similar deviations values, the average values in SLS technology is equal $-0.083 \mathrm{~mm}$. It is also related to the high temperature of the building chamber and difficulties in cooling process.

\section{Conclusions}

These studies clearly show that the direction of the models' location and their geometrical features fundamentally affects the accuracy. The most favourable variant of the location of geometric features in the case of internal cylindrical surfaces is $90^{\circ}$. The least advantageous variant is the position of features at an angle of $45^{\circ}$, where the so-called "collapse" of the material under the influence of the change in material density in the sintered state is strongly visible. The flatness measurement of the tested surfaces clearly indicates that the direction of their inclination affects shape tolerance deviations. It is clearly visible that variants B1-E1 show much larger deviations of flatness in comparison to the second variant i.e. B2-E2. The flatness value is an about $0.1 \mathrm{~mm}$ what is equal to the layer thickness.

In the future it is plan to include additional technological parameters (energy density, layer thickness and laser parameters) and their influence on the accuracy of manufacturing models.

\section{Acknowledgments}

The paper has been elaborated within the framework of the research project entitled "Theoretical and experimental problems of integrated 3D measurements of elements' surfaces”, reg. no.: 2015/19/B/ST8/02643, ID: 317012, financed by the National Science Centre, Poland. 


\section{References}

[1] Adamczak, S.; Stępień, K. \& Wrzochal, M. (2017). Comparative study of measurement systems used to evaluate vibrations of rolling bearings, Procedia Engineering Journal Elsevier, Vol. 192, pp. 971-975., https://doi.org/10.1016/j.proeng.2017.06.167

[2] Adamczak, S.; Zmarzły, P., Kozior, T. \& Gogolewski, D. (2017). Assessment of roundness and waviness deviations of elements produced by selective laser sintering technology, 23rd Int. Conf. on Engineering Mechanics 2017, Svratka, Czech Republic pp. 70-73.

[3] Kozior, T.; Döpke, C.,Grimmelsmann, N., Junger, I.J., Ehrmann, A. (2018). Influence of fabric pretreatment on adhesion of three-dimensional printed material on textile substrates. Advances in Mechanical Engineering, Vol. 10, pp. 1-8. https://doi.org/10.1177/1687814018792316

[4] Fafenrot, S.; Grimmelsmann, N., Wortmann, M. \& Ehrmann, A. (2017). Three-Dimensional (3D) Printing of Polymer-Metal Hybrid Materials by Fused Deposition Modeling, Materials (Basel), Vol. 10, pp. 1-14., doi: 10.3390/ma10101199

[5] Kundera, Cz. \& Bochnia, J. (2014). Investigating the stress relaxation of photopolymer O-ring seal models, Rapid Prototyping Journal, Vol. 20, 6, pp. 533-540., doi.org/10.1108/RPJ-04-2013-0043

[6] Leu, M.C. \& Guo, N. (2013). Additive manufacturing: technology, applications and research needs, Frontiers of Mechanical Engineering, Vol. 8, pp. 215-243., doi.org/10.1007/s11465-013-0248-8

[7] Liu, Z.H.; Nolte, J.J., Packard, J.I., Hilmas, G., Dogan, F. \& Leu, M.C. (2007). Selective Laser Sintering of Highdensity Alumina Ceramic Parts, Proceedings of the 35th International MATADOR Conference. Springer, London, doi.org/10.1007/978-1-84628-988-0_79

[8] Nowakowski, Ł.; Miko, E. \& Skrzyniarz, M. (2017). Designation of the minimum thickness of machined layer for the milling process of Duralumin PA6, 23rd Int. Conf. on Engineering Mechanics 2017, Svratka, Czech Republic pp. 722-725.

[9] Pilipović, A.; Valentan, B., Brajlih, T., Haramina, T., Balić, J., Kodvanj, J., Sercer, M. \& Drstvenśek, I. (2010). Influence of laser sintering parameters on mechanical properties of polymer products, Annals of DAAAM for 2010 \& Proceedings of the 21st International DAAAM Symposium, Vol. 21, pp.1-2.

[10] Salmoria, G. V.; Leite, J.L., Veira, L.F., Pires, A.T.N. \& Roesler, C.R.M. (2012). Mechanical properties of PA6/PA12 blend specimens prepared by selective laser sintering, Polymer Testing, Vol. 31, pp. 411-416., doi.org/10.1016/j.polymertesting.2011.12.006

[11] Salmoria, G. V.; Leite, J.L., Paggi, R.A., Lago, A. \& Pires, A.T.N. (2008). Selective laser sintering of PA 12/HDPE blends: Effect of components on elastic/plastic behavior, Polymer Testing, Vol. 27, pp. 654-659., doi.org/10.1016/j.polymertesting.2008.04.007

[12] Stopyra, W.; Kurzac, J., Gruber, K., Kurzynowski, T. \& Chlebus, E. (2016). Influence of laser power on the penetration depth and geometry of scanning tracks in selective laser melting, Laser Technology 2016: Progress and Applications of Lasers, Book Series: Proceedings of SPIE, 10159., DOI: 10.1117/12.2262079

[13] Takosoglu, J.; Łaski, P., Błasiak, S., Bracha, B. \& Pietrala, D. (2016). Determining the static characteristics of pneumatic muscles, Measurement and Control, Vol. 49, pp 62-71., DOI: 10.1177/0020294016629176

[14] Wang, R.; Wang, L., Zhao, L. \& Liu, Z. (2007). Influence of process parameters on part shrinkage in SLS, International Journal of Advanced Manufacturing Technology, Vol. 33, pp. 498-504., doi.org/10.1007/s00170-0060490-x

[15] Whitehouse D.J. (2011). Handbook of Surface and Nanometrology - second edition,

[16] Kozior, T. \& Kundera, Cz. (2017). Evaluation of the influence of parameters of FDM technology on the selected mechanical properties of models. Procedia Engineering, Vol. 192, pp. 463-468.

[17] Kundera, Cz. \& Kozior, T. (2014). Elastic bellows prepared by selective laser sintering. Applied Mechanics and Materials, Vol. 630 (2014), pp. 318-325.

[18] Bochnia, J. \& Blasiak, S. (2018). Fractional relaxation model of materials obtained with selective laser sintering technology. Rapid Prototyping Journal, Vol. 25, pp. 76-86., https://doi.org/10.1108/RPJ-11-2017-0236

[19] Budzik, G.; Burek, J., Bazan, A., Turek, P. (2016). Analysis of the Accuracy of Reconstructed Two Teeth Models Manufactured Using the 3DP and FDM Technologies. Strojniški Vestnik - Journal of Mechanical Engineering, Vol. 62, pp. 11-20.

[20] Jurjevic, M.; Krsulja, M., Katalinic, B., Car, Z., Sikulec, L. (2012). Automatic measurement of rotational speeds and lathe maintenance. Annals of DAAAM and Proceedings, Vol. 23, pp.775-778. 